\title{
Determinants of gender disparities in scaling up the first 90 towards the UNAIDS 90-90-90 targets in South Africa: findings from the 2017 household-based national cross-sectional
} survey

S. Jooste ${ }^{1,2^{*}} \mathbb{D}$, M. Mabaso ${ }^{1}$, M. Taylor ${ }^{2}$, A. North ${ }^{1}$, Y. L. Shean ${ }^{1}$ and L. C. Simbayi ${ }^{3,4}$

\begin{abstract}
Background: The first 90 of UNAIDS 90-90-90 targets to have 90\% of the people living with HIV know their status is an important entry point to the HIV treatment cascade and care continuum, but evidence shows that there is a large gap between males and females in this regard. It is therefore important to understand barriers and facilitators of achieving the first 90 target. This study examined determinants of the first 90 target among females and males in order to inform strategies aimed at improving the HIV cascade in South Africa.
\end{abstract}

Methods: The data used in the analysis were obtained from a 2017 household-based cross-sectional nationally representative survey conducted using a multi-stage stratified cluster random sampling design. A series of hierarchical multiple logistic regression models were fitted to identify the determinants of the first 90 target by gender.

Results: Overall, 84.8\% of HIV-positive individuals aged 15 years and older were aware of their HIV status. Females were significantly more aware of their HIV status compared to males ( $88.7 \%$ vs $78.2 \%, p<0.001)$. Both females aged 25 to 49 years [aOR $=3.20(95 \% \mathrm{Cl} 1.35-7.57), \mathrm{p}=0.008]$, and 50 years and older [aOR $=3.19(95 \% \mathrm{Cl} 1.04-9.76)$, $\mathrm{p}=0.042$ ] and males aged 25 to 49 years [aOR $=3.00$ (95\% Cl 1.13-7.97), $\mathrm{p}=0.028$, and 50 years and older $[\mathrm{aOR}=7.25$ (95\% Cl 2.07-25.36), $\mathrm{p}=0.002$ ] were significantly more likely to know their HIV status compared to those aged 15 to 19 years. Males with tertiary education level were significantly more likely to be aware of their HIV positive status [aOR $=75.24$ ( $95 \% \mathrm{Cl}$ 9.07-624.26), $\mathrm{p}<0.001$ ] compared to those with no education or with primary level education. Females with secondary $[\mathrm{aOR}=3.28(95 \% \mathrm{Cl} 1.20-8.99), \mathrm{p}=0.021]$ and matric $[\mathrm{aOR}=4.35(95 \% \mathrm{Cl}$ 1.54-12.37), $p=0.006$ ] educational levels were significantly more likely to be aware of their HIV positive status, compared to those with no education or with primary level education.

Conclusion: Significant progress has been made with regards to reaching the UNAIDS first 90 target. In this context achieving the first 90 target is feasible but there is a need for additional interventions to reach the males especially youth including those with no education or low levels of education.

\footnotetext{
*Correspondence: sjooste@hsrc.ac.za

1 Human and Social Capabilities Research Division, Human Sciences Research Council, 118 Buitengracht St, Cape Town City Centre, Cape Town 8000, South Africa

Full list of author information is available at the end of the article
}

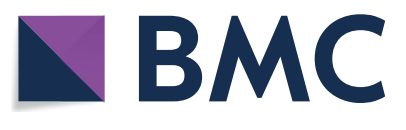

(c) The Author(s) 2021. This article is licensed under a Creative Commons Attribution 4.0 International License, which permits use, sharing, adaptation, distribution and reproduction in any medium or format, as long as you give appropriate credit to the original author(s) and the source, provide a link to the Creative Commons licence, and indicate if changes were made. The images or other third party material in this article are included in the article's Creative Commons licence, unless indicated otherwise in a credit line to the material. If material is not included in the article's Creative Commons licence and your intended use is not permitted by statutory regulation or exceeds the permitted use, you will need to obtain permission directly from the copyright holder. To view a copy of this licence, visit http://creativeco mmons.org/licenses/by/4.0/. The Creative Commons Public Domain Dedication waiver (http://creativecommons.org/publicdomain/ zero/1.0/) applies to the data made available in this article, unless otherwise stated in a credit line to the data. 
Keywords: HIV testing and awareness, 90-90-90 UNAIDS targets, Gender, South Africa

\section{Background}

The Joint United Nations Programme on HIV/AIDS' (UANIDS') 90-90-90 strategy is to end the HIV epidemic by 2030 by achieving three targets, $90 \%$ of all people living with HIV know their status; $90 \%$ of all people diagnosed with HIV receive sustained antiretroviral therapy (ART); and $90 \%$ of all people on ART are virally suppressed [1]. The first 90 target is an important entry point to the HIV treatment cascade and care continuum [2]. This includes diagnosis and linkage to care, retention in care, adherence to ART, and viral suppression needed to remain healthy and live a long life with HIV $[2,3]$.

The South African government also adopted this strategy and has made tremendous progress towards the UNAIDS 90-90-90 targets, where knowledge of HIV status is the first step towards progress in the HIV cascade $[2,4,5]$. Although there has been a remarkable increase in HIV testing and awareness over the past decades more remains to be done to end the HIV epidemic by 2030. In sub-Saharan Africa (SSA), men account for $41 \%$ of people living with HIV and $53 \%$ of the AIDS-related deaths in 2016 were men [6]. Various socio-demographic, behavioural, and social characteristics have been associated with knowledge of HIV status. These include among others gender, age, marital status, educational level, employment status, socio-economic status, area of residence, stigma, and discrimination $[5,7,8]$.

In Eastern and Southern African countries including South Africa, evidence points to large gaps between males and females in HIV testing and awareness including factors associated with the gender gap [5, 7, 9]. Understanding factors related to gender inequality in shaping the knowledge of HIV positive status is critical for designing interventions needed to bridge this gap, and for improving the HIV treatment and care cascade in South Africa. However, there is a paucity of nationally representative evidence. Therefore, more research is needed to understand the effects of various determinants related to gender inequality in influencing the testing and awareness of HIV status among people living with HIV. This paper examined the determinants of the first 90 target among females and males to inform strategies aimed at improving the HIV treatment and care cascade in South Africa.

\section{Methods \\ Study data and sampling}

The data used in the analysis were obtained from a nationally representative population-based household survey that was conducted in 2017 using a multi-stage stratified random cluster sampling design described in detail elsewhere [5]. A total of 1000 small area layers (SALs) were used as the primary sampling unit, drawn from the master sample through stratified, disproportionate sampling. The selection of SALs was stratified by province, locality type (urban areas, rural informal and formal areas), and race group. A total of 15 visiting points (VPs) were randomly selected from each of 1000 SALs, targeting 15,000 VPs. Of these, 12,435 (82.9\%) VPs were approached. Among these VPs, 11,776 (94.7\%) were valid VPs. A household response rate of 82.2\% was achieved from the valid VPs (Simbayi et al. 2019). All consenting members of the selected household formed the ultimate sampling unit.

\section{Study procedure}

The survey collected data using a household questionnaire and three age-appropriate questionnaires were administered to consenting individuals. For those younger than 18 years of age, consent was given by parents/guardians and assent by the participant. The interview instruments solicited information among others on socio-demographic characteristics, HIV-related knowledge, attitudes, and behaviours, including questions on HIV testing. The questionnaires were fieldworker administered and electronically captured using CSPro software on Mercer tablets. Fieldworkers also collected dried blood specimen samples from participants using a finger prick.

\section{HIV testing}

Fieldworkers also collected dried blood specimen samples from participants using a finger prick. Samples were sent to a centralised laboratory for HIV antibodies testing using an algorithm with three different enzyme immunoassays (EIAs). All samples testing HIV positive during the first two EIAs (Roche Elecys HIV Ag/Ab assay, Roche Diagnostics, Mannheim, Germany and Genescreen Ultra HIV Ag/Ab assay, Bio-Rad Laboratories, California, USA) were subjected to a nucleic acid amplification test (COBAS AmpliPrep/Cobas Taqman HIV-1 Qualitative Test, v2.0, Roche Molecular Systems, New Jersey, USA) for the final interpretation of test results. Testing 
for exposure to antiretroviral drugs (ARVs) in HIV-positive specimens was performed using High-Performance Liquid Chromatography (HPLC) coupled with Tandem Mass Spectrometry.

\section{Ethical consideration}

The survey protocol was approved by the Human Sciences Research Council (HSRC) Research Ethics Committee (REC: 4/18/11/15), and both the Division of Global HIV and TB (DGHT) and the Center for Global Health (CHG) of the Centers for Disease Control and Prevention (CDC). Ethical clearance was also obtained from the University of KwaZulu-Natal's Biomedical Research Ethics Committee (BE 646/18). Verbal or written informed consent was sought before undertaking both the behavioural data and blood specimen collection.

\section{Measures}

\section{Dependent variable}

The primary outcome variable, the first 90 of the UNAIDS 90-90-90 targets [1] was defined as people who have been diagnosed HIV positive in the central laboratory and knew their status or were exposed to antiretrovirals, dichotomized as diagnosed and aware of HIV status $=1$ and diagnosed and not aware of HIV status $=0$.

\section{Independent variables}

Explanatory variables were socio-demographic and HIV related behavioural characteristics. Socio-demographic characteristics included age group (15-19, 20-24, 25-49, 50 years and older), race groups (African and other race groups), marital status (married, never married), level educational qualification (no education/primary, secondary, matric, tertiary), employment (yes, no), and locality type (urban areas, rural informal/tribal areas, rural formal/farms). HIV related behaviour characteristics included condom use last sex act (yes, no), correct HIV knowledge and myth rejection (yes, no), and self-perceived risk of HIV infection (yes, no).

\section{Statistical analysis}

Descriptive statistics were used to summarize the sample characteristics. Proportion tests "prtest" command were used to test for differences between the explanatory variables and the first 90 target by gender. A series of hierarchical multiple logistic regression models structured by sex (males and females) were fitted, and the estimates of the contributions of each independent variable were computed against the dependent variable in successive models. The best-fitting models with variables that reliably predict the first 90 target were determined by assessing changes in R-squared (R2) values and best predictors by adjusted odds ratios (aOR) with $95 \%$ confidence intervals (CIs) and $\mathrm{p} \leq 0.05$. The 'svy' command was used to introduce weights that take into account the complex design of the survey. All data analyses were conducted using STATA version 15.0 (STATACORP, College Station, TX) software.

\section{Results \\ Sample characteristics}

Figure 1 shows the sub-sample of those who tested for HIV and the breakdown of the first 90 the primary outcome of interest in the study.

Table 1 shows the summary statistics of the study sample and the first 90 target. Of 2819 individuals (males, $\mathrm{n}=808$ and females, $\mathrm{n}=2011$ ) that tested HIV positive in the survey. The majority were aged 25 to 49 years of age $(74.8 \%)$, were Black African (96.1\%), were not married $(78.4 \%)$, were unemployed (66.2\%), and resided in urban areas (62.2\%). Less than half (45.2\%), had completed secondary level education, more than half (52.3\%) used a condom at last sex, while the majority did not have accurate knowledge about preventing HIV transmission and rejection of misconceptions (64.8\%) and had a low self-perceived risk of becoming HIV infected (74.3\%). The characteristics of males and females that tested HIV positive were similar to the overall sample except that more males were married (28.3\% vs $17.8 \%)$ and employed ( $47.1 \%$ vs $26.2 \%$ ) compared to females.

Table 2 shows that a large majority $(84.8 \%)$ of the HIV positive sample were aware of their HIV status. Higher awareness of HIV status was found among those aged 25 to 49 years, Black African and people living in urban areas, those who were married, had matric or higher education, were unemployed and used a condom at last sex achieved the first UNAIDS 90 target. Females had a significantly higher awareness of HIV status compared to males $(88.7 \%$ vs $78.2 \%, \mathrm{p}<0.001)$. Testing and awareness of HIV status among females relative to males were significantly higher by race, marital status, employment status, locality type, condom use at last sex, HIV knowledge, and risk perception. Females in the 15 to 19 year and 25 to 49 year age groups had significantly higher awareness than males in the same age groups $(\mathrm{p}<0.001)$. Females with secondary and matric level education had a higher awareness of their HIV status than their male counterparts with the same level of education $(\mathrm{p}<0.001)$.

\section{Hierarchical regression models}

Figure 2 shows the results of the multiple hierarchical regression models of factors associated with testing positive for HIV and being aware of their status (UNAIDS' first 90 target) among males and females aged 15 years and older. Males $25-49$ years [aOR $=3.00$ 


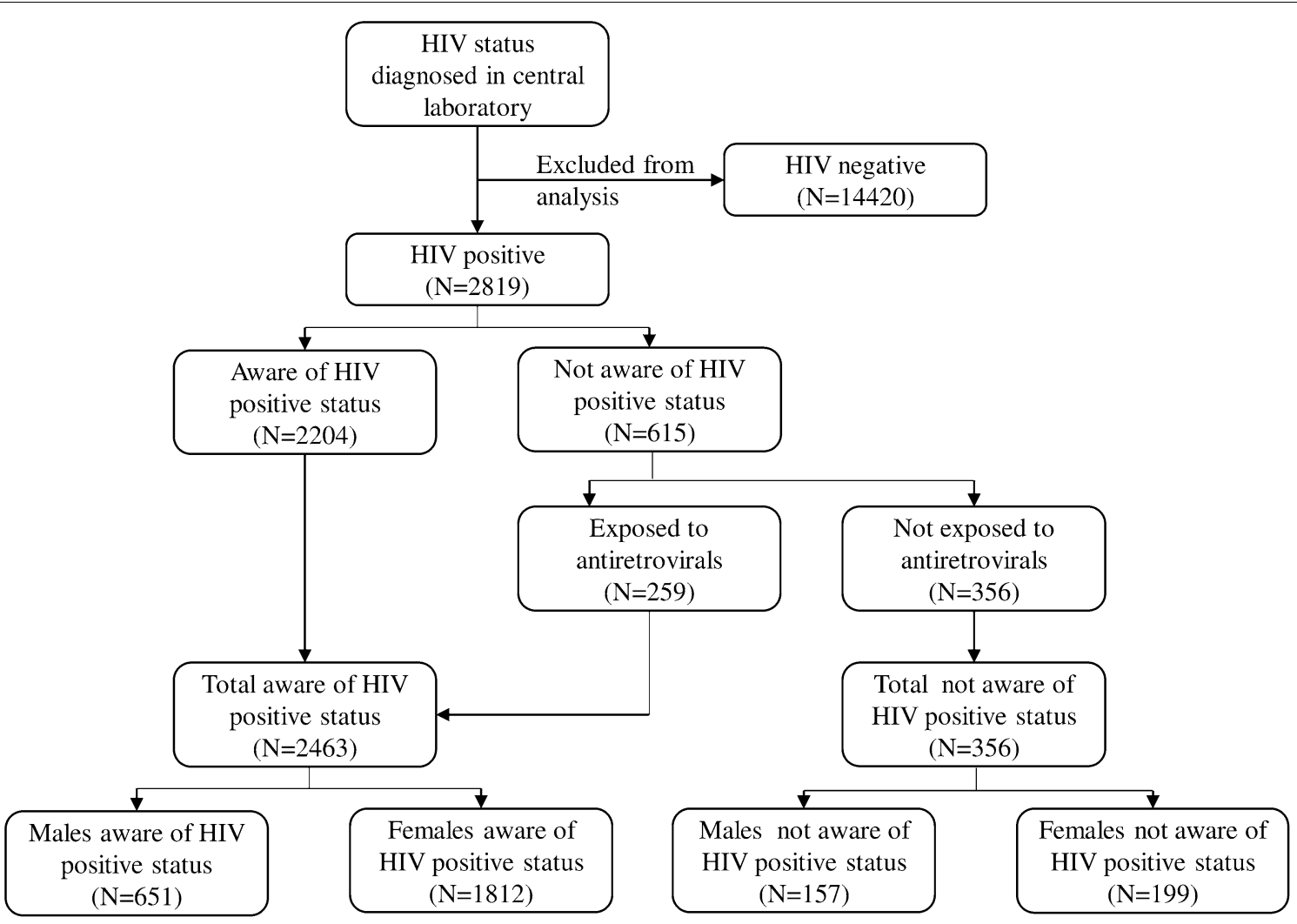

Fig. 1 Description of first 90 (people living with HIV who know their HIV) by sex

(95\% CI 1.13-7.97), $\mathrm{p}=0.028$ ], those 50 years and older [aOR $=7.25$ (95\% CI 2.07-25.36), $\mathrm{p}=0.002$ ] were significantly more likely to be aware of their HIV positive status compared to those 15-19 years. In addition, males with tertiary educational qualifications were significantly more likely to be aware of their HIV positive status $[\mathrm{aOR}=75.24$ (95\% CI 9.07-624.26), $\mathrm{p}<0.001]$ compared to those with no education or with primary level education.

Similarly, females 25-49 years [aO $=3.20$ (95\% CI $1.35-7.57), \mathrm{p}=0.008$ ] and those 50 years and older [aOR $=3.19$ (95\% CI 1.04-9.76), $\mathrm{p}=0,042$ ] were significantly more likely to be aware of their HIV positive status compared to those 15-19 years. Furthermore, females with secondary $[\mathrm{aOR}=3.28$ (95\% CI $1.20-$ 8.99), $\mathrm{p}=0.021$ ] and matric $[\mathrm{aOR}=4.35(95 \% \mathrm{CI}$ 1.54-12.37), $\mathrm{p}=0.006$ ] educational qualifications were significantly more likely to be aware of their HIV positive status compared to those with no education or with primary level education

\section{Discussion}

In this representative national survey, more than three quarters $(84.8 \%)$ of the HIV-positive youth and adult population were already diagnosed at the time of the survey and were aware of their status. These results were higher than data from countries in other population surveys in the Eastern and Southern African sub-regions [10]. Overall, awareness of HIV positive status was higher among those aged 25 to 49 years, Black African and people living in urban areas, those who were married, had matric or higher education, were unemployed and used a condom at last sex, who achieved the first UNAIDS' 90 target.

This study also confirmed that the proportion of youth and adults diagnosed and aware of their HIV positive status was significantly higher among females compared to males for all the above socio-demographic and sociobehavioural factors. Evidence shows that Black African females are more likely to have an HIV test in their lifetime than their male counterparts, due to their exposure 
Table 1 Characteristics of the study sample aged 15 years and older who tested HIV positive and were aware of their status by gender, South Africa 2017

\begin{tabular}{|c|c|c|c|c|c|c|}
\hline \multirow[t]{2}{*}{ Variables } & \multicolumn{2}{|l|}{ Total } & \multicolumn{2}{|c|}{ Males } & \multicolumn{2}{|c|}{ Females } \\
\hline & $\mathbf{n}$ & $\%$ & $\mathbf{n}$ & $\%$ & $\mathbf{n}$ & $\%$ \\
\hline \multicolumn{7}{|l|}{ Age categories } \\
\hline $15-19$ & 110 & 3.2 & 36 & 3.9 & 74 & 2.8 \\
\hline $20-24$ & 226 & 6.9 & 51 & 4.4 & 175 & 8.3 \\
\hline $25-49$ & 1959 & 74.8 & 558 & 75.5 & 1401 & 74.5 \\
\hline $50+$ & 524 & 15.0 & 163 & 16.1 & 361 & 14.4 \\
\hline \multicolumn{7}{|l|}{ Race } \\
\hline Black African & 2573 & 96.1 & 730 & 94.9 & 1843 & 96.8 \\
\hline Other & 246 & 3.9 & 78 & 5.1 & 168 & 3.2 \\
\hline \multicolumn{7}{|l|}{ Currently married } \\
\hline Married & 579 & 21.6 & 228 & 28.3 & 351 & 17.8 \\
\hline Not married & 2065 & 78.4 & 525 & 71.8 & 1540 & 82.2 \\
\hline \multicolumn{7}{|l|}{ Education level completed } \\
\hline No education/primary & 592 & 20.4 & 193 & 21.2 & 399 & 19.9 \\
\hline Secondary level education & 1075 & 45.2 & 312 & 46.7 & 763 & 44.3 \\
\hline Matric & 590 & 28.9 & 144 & 25.7 & 446 & 30.7 \\
\hline Tertiary level education & 118 & 5.6 & 35 & 6.4 & 83 & 5.1 \\
\hline \multicolumn{7}{|l|}{ Employment status } \\
\hline Unemployed & 1749 & 66.2 & 388 & 52.9 & 1361 & 73.9 \\
\hline Employed & 865 & 33.8 & 358 & 47.1 & 507 & 26.2 \\
\hline \multicolumn{7}{|l|}{ Locality type } \\
\hline Urban areas & 1505 & 62.2 & 440 & 65.9 & 1065 & 60.1 \\
\hline Rural informal areas & 899 & 30.7 & 198 & 23.2 & 701 & 35.1 \\
\hline Rural farms & 415 & 7.1 & 170 & 11.0 & 245 & 4.9 \\
\hline \multicolumn{7}{|l|}{ Condom use last sex act } \\
\hline No & 778 & 47.8 & 225 & 46.1 & 553 & 48.8 \\
\hline Yes & 765 & 52.3 & 249 & 53.9 & 516 & 51.2 \\
\hline \multicolumn{7}{|c|}{ Correct knowledge and myth rejection } \\
\hline No & 1701 & 64.8 & 477 & 65.1 & 1224 & 64.7 \\
\hline Yes & 941 & 35.2 & 274 & 34.9 & 667 & 35.3 \\
\hline \multicolumn{7}{|l|}{ Self-perceived risk of HIV } \\
\hline Low & 1090 & 74.3 & 374 & 79.3 & 716 & 70.8 \\
\hline High & 366 & 25.8 & 99 & 20.7 & 267 & 29.2 \\
\hline
\end{tabular}

to sexual reproductive health services $[5,8,11,12]$. This suggests that greater exposure to HIV testing is associated with higher awareness of HIV status [8]. This implies that encouraging routine HIV testing and awareness may be especially challenging for males who are less likely than females to engage in preventive health care overall $[5,11,12]$.

These findings are consistent with other studies conducted across sub-Saharan Africa (SSA). The 20152016 Malawi Population-based HIV Impact Assessment [6] found that men were $12 \%$ less like to know their HIV status than women, and a third lower in Niger and
Paraguay among men living with HIV than women living with HIV. These findings point to harmful hegemonic gender norms and stereotypes that emphasise men's invulnerability to illness, their masculinity and male dominance contribute to poor health outcomes and discourage them to know their status [13]. Gender, defined as the "socially constructed roles, behaviour, activities and attributes that a particular society considers appropriate for men and women" [14] has been identified as a social structure which is deeply embedded at all levels of society [15], and plays a central role in the HIV/AIDS epidemic [16]. Men were found to be resistant to HIV testing and prevention efforts [17] 
Table 2 Sample characteristics of individuals diagnosed HIV positive and aware (UNAIDS' first 90 target) among youth and adults 15 years and older by sex, South Africa 2017

\begin{tabular}{|c|c|c|c|c|c|c|c|c|c|c|}
\hline \multirow[t]{2}{*}{ Variables } & \multicolumn{3}{|c|}{$\begin{array}{l}\text { Total sample diagnosed and } \\
\text { aware }\end{array}$} & \multicolumn{3}{|c|}{ Males diagnosed and aware } & \multicolumn{3}{|c|}{ Females diagnosed and aware } & \multirow[b]{2}{*}{ p-value } \\
\hline & $\mathbf{N}$ & $\%$ & $95 \% \mathrm{Cl}$ & $\mathbf{n}$ & $\%$ & $95 \% \mathrm{Cl}$ & $\mathbf{n}$ & $\%$ & $95 \% \mathrm{Cl}$ & \\
\hline Total & 2819 & 84.8 & $81.6-87.6$ & 808 & 78.2 & $72.4-83.1$ & 2011 & 88.7 & $85.7-91.1$ & $<0.001$ \\
\hline \multicolumn{11}{|l|}{ Age categories } \\
\hline $15-19$ & 110 & 75.2 & $63.6-84.0$ & 36 & 62.8 & $44.0-78.5$ & 74 & 85.1 & $73.7-92.1$ & 0.008 \\
\hline $20-24$ & 226 & 73.4 & $59.4-83.9$ & 51 & 73.2 & $56.0-85.4$ & 175 & 73.5 & $55.6-86.0$ & 0.966 \\
\hline $25-49$ & 1959 & 85.8 & $82.2-88.8$ & 558 & 77.6 & $70.7-83.3$ & 1401 & 90.6 & $87.0-93.4$ & $<0.001$ \\
\hline $50+$ & 524 & 87.3 & $81.4-91.5$ & 163 & 86.2 & $76.0-92.4$ & 361 & 88.0 & $82.0-92.2$ & 0.565 \\
\hline \multicolumn{11}{|l|}{ Race } \\
\hline Black African & 2573 & 85.3 & $82.1-88.0$ & 730 & 78.8 & $72.8-83.8$ & 1843 & 89 & $85.9-91.5$ & $<0.001$ \\
\hline Other & 246 & 73.1 & $54.1-86.2$ & 78 & 66.6 & $43.4-83.9$ & 168 & 79 & $60.2-90.4$ & 0.036 \\
\hline \multicolumn{11}{|l|}{ Marital status } \\
\hline Married & 579 & 91.8 & $87.8-94.6$ & 228 & 87.4 & $79.6-92.4$ & 351 & 95.8 & $92.6-97.7$ & $<0.001$ \\
\hline Not married & 2065 & 88.9 & 86.4-91.1 & 525 & 83.0 & $77.8-87.2$ & 1540 & 91.9 & 88.9-94.2 & $<0.001$ \\
\hline \multicolumn{11}{|l|}{ Education level } \\
\hline No education & 592 & 84.3 & $76.5-89.8$ & 193 & 82.4 & $73.5-88.8$ & 399 & 85.4 & $72.9-92.7$ & 0.345 \\
\hline Secondary level & 1075 & 89.9 & $86.9-92.2$ & 312 & 82.6 & $75.9-87.8$ & 763 & 94.3 & $91.8-96.0$ & $<0.001$ \\
\hline Matric & 590 & 92.6 & $89.7-94.8$ & 144 & 86.0 & 77.9-91.5 & 446 & 95.9 & $93.6-97.3$ & $<0.001$ \\
\hline Tertiary level & 118 & 97.4 & $91.9-99.2$ & 35 & 99.7 & $97.7-100.0$ & 83 & 95.7 & $86.4-98.7$ & 0.253 \\
\hline \multicolumn{11}{|l|}{ Employment status } \\
\hline Unemployed & 1749 & 90.0 & $87.3-92.2$ & 388 & 85.7 & $80.7-89.5$ & 1361 & 91.8 & $88.4-94.3$ & $<0.001$ \\
\hline Employed & 865 & 88.9 & $85.6-91.6$ & 358 & 83.3 & $77.1-88.1$ & 507 & 94.7 & $92.0-96.6$ & $<0.001$ \\
\hline \multicolumn{11}{|l|}{ Locality type } \\
\hline Urban areas & 1505 & 87.7 & $84.5-90.2$ & 440 & 82.8 & $77.1-87.3$ & 1065 & 90.7 & $87.5-93.2$ & $<0.001$ \\
\hline Rural informal areas & 899 & 85.8 & $80.3-89.9$ & 198 & 79.7 & $68.5-87.6$ & 701 & 88.1 & $81.7-92.5$ & 0.002 \\
\hline Rural formal areas & 415 & 56.2 & $37.7-73.1$ & 170 & 47.3 & $27.8-67.7$ & 245 & 67.7 & $51.3-80.6$ & $<0.001$ \\
\hline \multicolumn{11}{|l|}{ Condom use last sex act } \\
\hline No & 778 & 88.9 & $85.6-91.5$ & 225 & 79.5 & $72.0-85.5$ & 553 & 94.6 & $91.9-96.5$ & $<0.001$ \\
\hline Yes & 765 & 94.3 & $91.4-96.2$ & 249 & 89.8 & $83.3-94.0$ & 516 & 97.3 & $95.1-98.6$ & $<0.001$ \\
\hline \multicolumn{11}{|c|}{ Correct knowledge and myth rejection } \\
\hline No & 1701 & 89.4 & $86.3-91.8$ & 477 & 85.5 & $80.5-89.5$ & 1224 & 91.6 & $87.7-94.3$ & $<0.001$ \\
\hline Yes & 941 & 89.9 & $86.9-92.3$ & 274 & 81.8 & $74.4-87.4$ & 667 & 94.5 & $92.2-96.2$ & $<0.001$ \\
\hline \multicolumn{11}{|c|}{ Self-perceived risk of HIV infection } \\
\hline Low & 1090 & 81.5 & $77.1-85.1$ & 374 & 75.8 & $68.7-81.7$ & 716 & 85.9 & $79.7-90.4$ & $<0.001$ \\
\hline High & 366 & 85.0 & $79.8-89.0$ & 99 & 75.6 & $62.7-85.1$ & 267 & 89.6 & $84.3-93.2$ & $<0.001$ \\
\hline
\end{tabular}

and that an HIV test was also seen as the impetus for change in behaviour and therefore undesirable among men [18].

The findings from logistic regression models indicated that a rather similar set of demographic factors were common among both males and females who tested HIV positive and were aware of their status in the current study. These findings suggest that age and education may influence HIV testing and awareness. Others found no significant association between gender and HIV testing and awareness but rather with age [19-21]. The youth were less likely to report having been tested and being aware of their status compared to the older age groups $[19,20]$. Young people (15 to 25 years of age) were also more likely to engage in risky sexual behaviours regardless of gender, and so represent the target population for most interventions and campaigns to improve HIV testing and awareness [20].

The current focus of the South African government and international agencies is on reducing the burden of HIV amongst adolescent females living with HIV. This study revealed that the group not currently linked to HIV treatment are those who are not aware of their status, which is concerning given that the essential step in the HIV care 


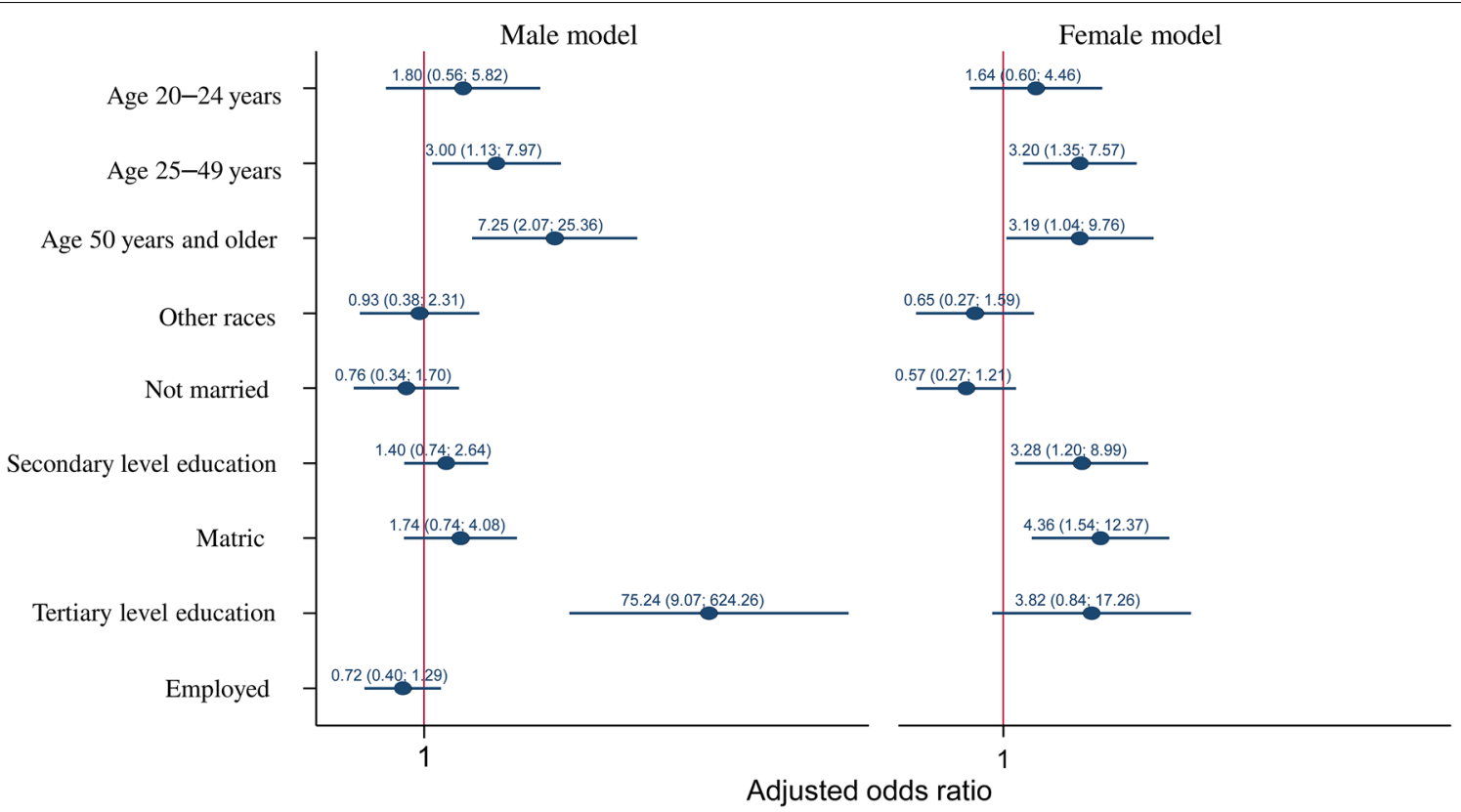

Fig. 2 Hierarchical logistic regression models of factors associated with UNAIDS'first 90 target, South Africa 2017

pathway for HIV-positive individuals starts with HIV testing [22]. This was worse among males compared to females with about $60 \%$ HIV positive adolescent males who were not aware of their status at a population level. In other words, more than a third of people living with HIV in this group could transmit the virus unless they are linked to care and provided with prevention tools and empowered to use them. The identified gap towards achieving the first 90 among adolescent males could not be ascertained using routine programme data. Therefore, this study provides vital strategic information on one of the key pillars of the 90-90-90 UNAIDS targets in the country.

Reaching the first UNAIDS target will require concerted efforts to increase the uptake of HIV testing by addressing accessibility of services through targeted selftesting, mobile and community-based testing [23-26]. Evidence suggests that the public nature of HIV testing campaigns influence men's uptake of testing with more preference for home-based testing [27, 28]. This reduces stigma and vulnerability attributable to attitudes or assumptions regarding individuals who request HIV testing in public venues or health centres [27]. Such engagement can facilitate social and interpersonal support by trusted friends, partners, and family members. It is therefore important to determine preferences of men for HIV testing in order to inform programs regarding where to focus male HIV testing resources and achieve greatest impact [27]. The provision of adolescent-friendly services is another strategy for encouraging HIV testing uptake among young men and a key component of national HIV responses.

In agreement with the current findings, the evidence shows that in impoverished communities both youth and adult males and females with greater educational attainment (high school diploma or greater) were more likely to report having been tested for HIV and were aware of their status than those who had no education or had not graduated from high school $[5,11,12]$. This suggests that educational level may not only influence one's likelihood to seek HIV testing but may also play a pivotal role in increasing awareness of ones's HIV status. This finding underscores the importance of formal education which is often viewed as an essential factor in the social determinants of health, especially in disadvantaged communities. Improving the level of education will not only inform HIV testing and awareness in impoverished communities but can also positively influence linkage to treatment and care in these communities.

While addressing the educational needs of impoverished communities is a potential strategy to increase HIV testing, there is also a need for providing initiatives to overcome barriers to testing among those with no formal education. The educated might have higher levels of exposure to HIV-related information, better knowledge of the advantages of HIV testing as well as ability to make good decision to go for HIV testing than their uneducated counterparts. These observations highlight the importance of providing health education including HIV-related information to those with low level or 
no education. An important dimension of bridging this gap is equity, which can be achieved through community outreach to facilitate HIV testing uptake through home, mobile and community-based strategies. Promoting HIV testing through community meetings among those with no formal education could be a cornerstone towards closing the testing gap and achieving the first ' 90 ' target.

This study has some limitations that should be noted. Explanatory data used in the analysis was self-reported and could be subject to recall and social desirability bias. The sample of HIV-diagnosed individuals who were aware of their status was smaller, and consequently part of the analysis lacked precision which is reflected in the large confidence intervals which are reflected in some of the results. This study was cross-sectional and was only limited to ascertaining the association between the primary outcome and potential explanatory variables and could not infer causality. As with any observational investigation, the study is limited in the number of variables and there may be other, unmeasured factors that contribute to the observed associations. Nevertheless, this study was based on a nationally representative population sample and the findings can be generalised to individuals diagnosed with HIV and who are aware of their status.

\section{Conclusion}

This study suggests an association between HIV testing and awareness with age and education level among both males and females as an important combination of factors that determine population groups and barriers that need to be targeted to make progress to achieving the first 90 of the UNAIDS targets towards ending HIV in 2030. The findings study revealed that the group not currently linked to HIV treatment are those who are not aware of their status, and this gap was huge among male adolescents compared to their counterparts as well as among those with little or no education. Substantial opportunities exist to optimize the uptake of HIV testing though innovative application of existing intervention strategies. A greater emphasis should be placed on promoting and increasing demand for the different HIV testing models as well as improving both formal and HIV related education as a means of reducing HIV testing and awareness disparities in the country towards improving the HIV treatment and care cascade in South Africa.

\section{Acknowledgements}

Not applicable

\section{Authors' contributions}

SJ drafted of the manuscript. SJ and MM performed the statistical analysis. Sean Jooste, MM, AN, YS and LS participated in the implementation of the survey that provided the data for the manuscript. All authors contributed to the review of draft manuscript and approved the final manuscript. All authors have read and approved the final manuscript

\section{Funding}

This manuscript was supported by the President's Emergency Plan for AIDS Relief (PEPFAR) through the Centers for Disease Control and Prevention, under the terms of Cooperative Agreement Number [NU2GGH001629] as well as the South African Department of Science and Technology, South African National AIDS Council (SANAC), Global Fund to Fight AIDS, Tuberculosis and Malaria, Right to Care, United Nations Children's Fund (UNICEF), Centre for Communication Impact, Soul City, and LoveLife. The findings and conclusions in this report are those of the author(s) and do not necessarily represent the official position of the funding agencies.

\section{Availability of data and materials}

The datasets analysed during the current study are available in the [SABSSM] repository, Human Sciences Research Council. South African National HIV Prevalence, HIV Incidence, Behaviour and Communication Survey (SABSSM) 2017: Combined - All provinces. [Data set]. SABSSM 2017 Combined. Version 1.0. Pretoria South Africa: Human Sciences Research Council [producer] 2017, Human Sciences Research Council [distributor] 2020. http://dx.doi.org/doi:10. $14749 / 1585345902$

\section{Compliance with ethical standards}

\section{Ethics approval and consent to participate}

The survey protocol was approved by the Human Sciences Research Council (HSRC) Research Ethics Committee (REC: 4/18/11/15), and both the Division of Global HIV and TB (DGHT) and the Center for Global Health (CHG) of the Centers for Disease Control and Prevention (CDC). Ethical clearance was also obtained from the University of KwaZulu-Natal's Biomedical Research Ethics Committee (BE 646/18). Verbal or written informed consent was sought before undertaking both the behavioural data and blood specimen collection.

\section{Consent for publication}

Not applicable

\section{Competing interests}

The authors declare that they have no competing interests

\section{Author details}

${ }^{1}$ Human and Social Capabilities Research Division, Human Sciences Research Council, 118 Buitengracht St, Cape Town City Centre, Cape Town 8000, South Africa. ${ }^{2}$ School of Nursing and Public Health, University of KwaZulu-Natal, Durban, South Africa. ${ }^{3}$ Deputy CEO for Research, Human Sciences Research Council, Cape Town, South Africa. ${ }^{4}$ Department of Psychiatry and Mental Health, University of Cape Town, Cape Town, South Africa.

Received: 30 November 2020 Accepted: 12 April 2021

Published online: 28 April 2021

\section{References}

1. UNAIDS. The gap report. Geneva: Joint United Nations Programme on HIV/AIDS: Joint United Nations Programme on HIV/AIDS. 2014.

2. Takuva S, Brown AE, Pillay Y, Delpech V, Puren AJ. The continuum of HIV care in South Africa: implications for achieving the second and third UNAIDS 90-90-90 targets. AIDS. 2017. https://doi.org/10.1097/QAD. 0000000000001340.

3. Kay ES, Batey DS, Mugavero MJ. The HIV treatment cascade and care continuum: updates, goals, and recommendations for the future. AIDS Res Ther. 2016. https://doi.org/10.1186/s12981-016-0120-0.

4. Lippman SA, El Ayadi AM, Grignon JS, Puren A, Liegler T, Venter WDF, et al. Improvements in the South African HIV care cascade: findings on 90-90-90 targets from successive population-representative surveys in North West Province. J Int AIDS Soc. 2019;22(6):e25295-e. https://doi.org/ 10.1002/jia2.25295

5. Simbayi LC, Zuma K, Zungu N, Moyo S, Marinda E, Jooste S, et al. South African national HIV prevalence, incidence, behaviour and communication survey, 2017. Cape Town: HSRC Press; 2019.

6. UNAIDS. Blind Spot: reaching out to men and boys-addreeing a blind spot in the HIV response to HIV. Geneva: Joint United Nations Programme on HIV/AIDS. 2017. 
7. Peltzer K, Matseke G, Mzolo T, Majaja M. Determinants of knowledge of HIV status in South Africa: results from a population-based HIV survey. BMC Public Health. 2009;9(1):174.

8. Woldesenbet S, Kufa T, Cheyip M, Ayalew K, Lombard C, Manda S, et al. Awareness of HIV-positive status and linkage to treatment prior to pregnancy in the "test and treat" era: a national antenatal sentinel survey, 2017, South Africa. PLos one. 2020;15(3):e0229874.

9. UNAIDS. Miles to go. Global AIDS update. Geneva: Joint United Nations Programme on HIV/AIDS. 2018.

10. UNAIDS. Ending AIDS: progress towards th 90-90-90 targets. Geneva: Joint United Nations Programme on HIV/AIDS. 2017.

11. Shisana O, Rehle T, Simbayi LC, Zuma K, Jooste S, Pillay-van-Wyk V, et al. South African national HIV prevalence, incidence, behaviour and communication survey 2008: a turning tide among teenagers. Cape Town: HSRC Press; 2009

12. Shisana O, Rehle T, Simbayi LC, Zuma K, Jooste S, Zungu N, et al. South African national HIV prevalence, incidence and behaviour survey, 2012. Cape Town: HSRC Press; 2014.

13. Mills EJ, Beyrer C, Birungi J, Dybul MR. Engaging men in prevention and care for HIV/AIDS in Africa. PLoS Med. 2012:9(2):e1001167.

14. WHO. Health topics: gender and health. Geneva: World Health Organization: World Health Organization. 2013.

15. Risman BJ. Gender as a social structure: theory wrestling with activism. Gend Soc. 2004;18(4):429-50.

16. Greig A, Peacock D, Jewkes R, Msimang S. Gender and AIDS: time to act. AIDS. 2008. https://doi.org/10.1097/01.aids.0000327435.28538.18.

17. MOHSW. Lesotho demographic and health survey 2009. Maseru, Lesotho: 2009. Maseru: Ministry of Health and Social Welfare (MOHSW) [Lesotho] and ICF Macro. 2010

18. DiCarlo AL, Mantell JE, Remien RH, Zerbe A, Morris D, Pitt B, et al. 'Men usually say that HIV testing is for women': gender dynamics and perceptions of HIV testing in Lesotho. Culture, Health Sex. 2014;16(8):867-82.

19. Rountree MA, Chen L, Brown A, Pomeroy EC. HIV testing rates and testing locations, by race and ethnicity. Health Soc Work. 2009;34(4):247-55.

20. Wallace SA, McLellan-Lemal E, Harris MJ, Townsend TG, Miller KS. Why take an HIV test? concerns, benefits, and strategies to promote hiv testing among low-income heterosexual African American young adults. Health Educ Behav. 2011:38(5):462-70.
21. Adekeye OA, Heiman HJ, Onyeabor OS, Hyacinth HI. The new invincibles: HIV screening among older adults in the US. PLOS ONE. 2012;7(8):e43618.

22. Kranzer K, Govindasamy D, Ford N, Johnston V, Lawn SD. Quantifying and addressing losses along the continuum of care for people living with HIV infection in sub-Saharan Africa: a systematic review. J Int AIDS Soc. 2012;15(2):17383

23. van Schaik N, Kranzer K, Wood R, Bekker LG. Earlier HIV diagnosis—are mobile services the answer? S Afr Med J. 2010;100(10):671-4.

24. Meehan S-A, Naidoo P, Claassens MM, Lombard C, Beyers N. Characteristics of clients who access mobile compared to clinic HIV counselling and testing services: a matched study from Cape Town, South Africa. BMC Health Serv Res. 2014;14(1):658.

25. Bassett IV, Regan S, Mbonambi H, Blossom J, Bogan S, Bearnot B, et al. Finding HIV in hard to reach populations: mobile HIV testing and geospatial mapping in Umlazi township, Durban South Africa. AIDS Behav. 2015;19(10):1888-95.

26. Labhardt ND, Motlomelo M, Cerutti B, Pfeiffer K, Kamele M, Hobbins MA, et al. Home-based versus mobile clinic HIV testing and counseling in rural Lesotho: a cluster-randomized trial. PLoS Med. 2014;11(12):e1001768.

27. Osoti AO, John-Stewart G, Kiarie JN, Barbra R, Kinuthia J, Krakowiak D, et al. Home-based HIV testing for men preferred over clinic-based testing by pregnant women and their male partners, a nested cross-sectional study. BMC Infect Dis. 2015;15(1):298.

28. Ndyabakira A, Getahun M, Byamukama A, Emperador D, Kabageni S, Marson K, et al. Leveraging incentives to increase HIV testing uptake among men: qualitative insights from rural Uganda. BMC public health. 2019:19(1):1763. http://europepmc.org/abstract/MED/31888589, https:// doi.org/https://doi.org/10.1186/s12889-019-8073-6, https://europepmc. org/articles/PMC6937741, https://europepmc.org/articles/PMC6937741? pdf=render.

\section{Publisher's Note}

Springer Nature remains neutral with regard to jurisdictional claims in published maps and institutional affiliations.
Ready to submit your research? Choose BMC and benefit from:

- fast, convenient online submission

- thorough peer review by experienced researchers in your field

- rapid publication on acceptance

- support for research data, including large and complex data types

- gold Open Access which fosters wider collaboration and increased citations

- maximum visibility for your research: over $100 \mathrm{M}$ website views per year

At BMC, research is always in progress.

Learn more biomedcentral.com/submissions 